\title{
Consórcios intermunicipais ou arranjos de desenvolvimento da educação? Uma análise de duas experiências no federalismo educacional brasileiro
}

\section{Eduardo José Grin}

Fundação Getulio Vargas (FGV), São Paulo - SP, Brasil

\section{Catarina lanni Segatto}

Universidade Federal do ABC, São Bernardo do Campo - SP, Brasil

Este artigo analisa dois modelos de associativismo territorial na educação brasileira no Estado de São Paulo: o Consórcio Intermunicipal do Vale do Paranapanema e o Arranjo de Desenvolvimento da Educação do Noroeste Paulista. Busca-se compreender as razões que levam municípios inseridos em contextos demográficos e socioeconômicos similares a escolherem diferentes tipos de cooperação territorial. A partir da literatura, definiu-se um modelo analítico com três dimensõeschave: contexto regional e trajetória do arranjo, desenho institucional e modelo de governança e mecanismos de financiamento e indução federativa. Utilizou-se a técnica dos casos mais similares, já que a diferença central está nos dois modelos de associativismo analisados, que é, portanto, a variável dependente. A investigação analisou dados secundários coletados em publicações e documentos e dados primários em entrevistas semiestruturadas com dirigentes do consórcio e do arranjo. A análise mostra que a escolha por um consórcio ou arranjo para atuação regional na educação explica-se pelas dimensões do modelo analítico proposto, especialmente pelos fatores endógenos: estão presentes nos dois casos o desenho institucional, o processo decisório e o modelo de governança e, em um deles, o papel da liderança regional. Apenas em um caso as condições contextuais ligadas à trajetória do arranjo foram relevantes e, em nenhum deles, os mecanismos de financiamento tiveram efeitos positivos.

Palavras-chave: consórcio intermunicipal, arranjo de desenvolvimento da educação, municípios 


\section{¿Consorcios intermunicipales o acuerdos de desarrollo educativo? Análisis de dos experiencias en el federalismo educativo brasileño}

Este artículo analiza dos modelos de asociativismo territorial en la educación brasileña en el Estado de São Paulo: el Consorcio Intermunicipal del Valle de Paranapanema y el Acuerdo de Desarrollo Educativo Paulista del Noroeste. Buscamos entender las razones que llevan a los municipios en contextos demográficos y socioeconómicos similares a elegir diferentes tipos de cooperación territorial, analizando sus similitudes y diferencias. A partir de la literatura, se definió un modelo analítico con tres dimensiones clave: contexto regional y trayectoria de arreglo, diseño institucional y modelo de gobernanza y mecanismos de financiación e inducción federativa. Se utilizó la técnica de los casos más similares, ya que la diferencia central son los dos modelos asociativos analizados como la variable dependiente. La investigación analizó datos secundarios recopilados en publicaciones y documentos y datos primarios en entrevistas semiestructuradas con líderes del consorcio y del arreglo. El análisis demuestra que la elección de un consorcio o arreglo para la acción regional en educación se explica por las dimensiones del modelo analítico propuesto, especialmente por los factores endógenos: el diseño institucional, el proceso de toma de decisiones y el modelo de gobernanza están presentes en ambos casos y, en uno de ellos, el rol del liderazgo regional. Solo en un caso las condiciones contextuales vinculadas a la trayectoria del arreglo fueron relevantes y en ninguno de ellos los mecanismos de financiamiento tuvieron efectos positivos.

Palabras clave: consorcio intermunicipal, arreglo de desarrollo educativo, municipios

\section{Inter-municipal consortium or education development arrangements? An analysis of two experiences in the Brazilian educational federalism}

The article analyzes two models of territorial associativism in Brazil's education in the state of São Paulo: the Intermunicipal Consortium of Paranapanema Valley and the Education Development Arrangement of the Noroeste Paulista. We seek to understand the reasons that lead municipalities within similar demographic and socioeconomic contexts to choose one of these types of territorial cooperation, analysing their similarities and differences. Based on the literature, we defined an analytical model with three key dimensions: regional context and trajectory of the arrangement, institutional design and governance model, and funding mechanisms and federal induction. The technique of the most similar cases was used, as the central difference is the two associativism models analyzed as the dependent variable. The research analyzed secondary data from publications and documents and primary data from in-depth interviews with leaders of the Consortium and the Arrangement. The findings show that the choice for a consortium or an arrangement for education is explained by the dimensions of the analytical model proposed, especially, endogenous factors: the institutional design, the decision-making process, and the governance model have featured both cases, and one of them included the path of the arrangement. In only one case, contextual conditions related to the arrangement's path were relevant and, in none of them, funding had positive effects.

Keywords: inter-municipal consortium, education development arrangement, municipalities 


\section{Introdução}

Nas Federações, usualmente existem diferentes tipos de relacionamentos intergovernamentais: verticais entre Governo Federal e entes subnacionais e horizontais entre jurisdições. Nesse sentido, formas de relacionamento horizontal entre municípios ganharam centralidade na literatura sobre federalismo e políticas públicas. Esses arranjos são mecanismos que equilibram a competição federativa e reduzem as assimetrias entre os entes, mas mantendo sua autonomia e a diversidade nas políticas subnacionais (FEIOCK; SCHOLTZ, 2009; BAKVIS; BROWN, 2010; WALLNER, 2014). Apesar da extensa literatura sobre relações intergovernamentais e associativismo, poucos estudos comparam diferentes modelos de arranjos associativos. Esse é o objetivo deste artigo, ao analisar duas experiências de associativismo intermunicipal na Educação. Busca-se compreender quais fatores influenciam a adoção de diferentes modelos de cooperação intermunicipal em uma mesma política pública e em contextos similares.

No Brasil, a cooperação intermunicipal se fortaleceu com a disseminação de experiências de consórcios nas últimas décadas. Algumas surgiram antes da Constituição Federal de 1988 (CF/88), mas se multiplicaram com a criação de mecanismos de indução estaduais e federal e, sobretudo, com a aprovação da Lei de Consórcios Públicos em 2005 (Coutinho, 2006; GRIN; ABRUCIO, 2016). Essa disseminação variou entre as políticas, sendo a saúde e os resíduos sólidos mais bem-sucedidas do que a educação, por exemplo. Na política educacional, o desenho institucional descentralizado, a trajetória de baixa cooperação e a duplicidade das redes de ensino estaduais e municipais, que coexistem no mesmo território (CURY, 2008) com pouca ou nenhuma coordenação, têm desincentivado o associativismo. A CF/88 e legislações posteriores definiram o "regime de colaboração", mas a diversidade nas relações intergovernamentais e a ausência de relacionamentos mais cooperativos ainda caracterizam essa política (SEgATTO, 2018; SEgATTO; ABRUCIO, 2018).

Os consórcios intermunicipais são pouco expressivos na educação: abrangiam apenas 6,7\% dos municípios em 2015. Todavia, nas últimas duas décadas, a cooperação intermunicipal na educação foi fortalecida por meio da criação dos Arranjos de Desenvolvimento da Educação (ADEs) (ABRUCIO, 2017). Em 2008, os ADEs surgiram como alternativa de cooperação entre municípios a partir da atuação de fundações e institutos 
empresariais. Esse modelo de cooperação federativa foi disseminado ao ser considerado uma solução para a melhoria do desempenho educacional e o aumento da escala de atuação nos municípios atendidos. Avaliou-se que os consórcios públicos não seriam adequados para o contexto da política educacional, pois os ADEs envolviam parcerias entre Secretarias Municipais e organizações da sociedade civil (CRUZ, 2014; RAMOS; ABRUCIO, 2012).

Esta pesquisa analisa o associativismo intermunicipal na educação básica a partir de duas questões: quais são as semelhanças e diferenças nos modelos de governança de um consórcio intermunicipal e de um ADE? Por que razões os municípios optam por um desses dois modelos? Busca-se compreender os fatores que afetaram as escolhas dos municípios, cujas condições contextuais socioeconômicas são similares, quanto às formas de associativismo adotadas. Comparou-se o Consórcio Intermunicipal do Vale do Paranapanema (Civap) e o ADE Noroeste Paulista por meio de uma pesquisa documental e análise de entrevistas semiestruturadas com gestores, ex-gestores e lideranças políticas.

Para abordar essas questões, o artigo está dividido em quatro seções, além desta introdução. A primeira apresenta o quadro de referência teórica com as dimensões de análise: 1) condições contextuais; 2) fatores endógenos; 3) mecanismos de indução. A segunda seção apresenta o desenho da pesquisa e os procedimentos metodológicos. $\mathrm{Na}$ terceira, os dois casos são discutidos a partir das dimensões de análise. Nas conclusões, a comparação da Câmara Técnica da Educação e do ADE Noroeste Paulista discute os fatores que influenciaram as escolhas municipais por um dos modelos de associativismo territorial, incluindo suas semelhanças e diferenças. Ademais, propõe-se um modelo analítico que pode ser testado em outras políticas públicas.

\section{Dimensões da análise teórica}

A literatura sobre associativismo territorial foi sistematizada nas seguintes dimensões analíticas: 1) condições contextuais (características regionais e trajetória); 2) fatores endógenos (desenho institucional, processo decisório, capacidades estatais, modelo de governança e liderança); 3) mecanismos de indução (fontes de financiamento e regras federativas). 
A primeira dimensão baseia-se no institucionalismo histórico e no conceito de dependência da trajetória: políticas públicas podem ser explicadas por "retornos crescentes" ou feedbacks positivos (ARTHUR, 1990; Pierson, 2004; HAlL; TAYLOR, 2003). $\mathrm{Na}$ sequência de eventos, os atores ajustam suas ações aos paradigmas existentes, o que acaba produzindo estabilidade nas políticas ao longo do tempo (PIERSON, 2004). Regularidades institucionais existem, mas os atores políticos podem optar por mudanças mais incrementais (WEIR, 2006; IMMERGUT, 1998). No caso do associativismo, cidades com experiências prévias de cooperação são mais propensas a entrarem em acordos futuros, pois há uma curva de aprendizado e confiança (DI PORTO; PATY, 2018) que pode facilitar esse comportamento (HALL; TAYLOR, 2003).

Além disso, as características sociais, políticas e econômicas dos municípios afetam a formação de arranjos associativos. Quanto mais heterogêneas forem, menor a chance de se organizarem coletivamente, pois as assimetrias de recursos e poder aumentam a incerteza e os desequilíbrios entre os participantes (FEIOCK, 2007, 2013; BAE; FEIOCK, 2012; FEIOCK; SCHOLZ, 2009). Quanto maiores forem as diferenças entre as cidades, maiores serão os custos de transação, dificultando a colaboração mútua (BEL; WARNER, 2016; Feiock, 2007; Frug, 2001; LoWery, 2000; Post, 2002; WARner; Hefetz, 2002). Nesse sentido, os benefícios do associativismo podem ser menos atrativos para as cidades mais ricas (CARR et al., 2017; TAVARES; FEIOCK, 2018).

Contudo, a propensão para cooperar aumenta quando há maior convergência entre os interesses dos municípios e custos menores na participação em arranjos com cidades financeiramente menos aquinhoadas (BEL; WARNER, 2016; CARR et al., 2017; HAWKINS, 2009, 2010; LOWERY, 2000; LUBELL et al., 2002). A heterogeneidade no porte populacional municipal também reduz as chances de associativismo (BEL; WARNER, 2016; HULST; MONTFORT, 2012). Pequenas cidades cooperam para partilhar o custo de prover serviços (BEL et al., 2014), o que pode não ser o caso das maiores (FEIOCK, 2007; HAWKINS, 2009; KWON; FEIOCK, 2010). O associativismo também pode decorrer da autonomia dos entes subnacionais, mas essa faculdade também pode aumentar a competição entre os entes. Nesse caso, a adoção de mecanismos de relacionamento intergovernamentais horizontais (WALLNER, 2014) para lidar com problemas comuns interjurisdicionais (ABRUCIO; SOARES, 2001; GRIN et al., 2016; LACYNSKI, 2012) pode ser a alternativa. 
A segunda dimensão de análise engloba os fatores endógenos (natureza jurídica, governança, processo decisório, arranjo organizacional, capacidades estatais municipais e liderança regional) (FEIOCK, 2007, 2013).

Questões legais da administração pública podem afetar a adoção de soluções organizacionais que criam novas estruturas (SELZNICK, 1984). Além disso, a existência de regras é essencial para que os acordos de cooperação intergovernamental possam ser criados (KLOK et al., 2018; HULST; MONFORT, 2007).

A governança se refere à capacidade de comando, coordenação e implementação de políticas. A institucionalização e a horizontalidade dos arranjos influenciam o modo como as decisões são tomadas e acatadas pelas jurisdições (AGRANOFF, 2001, 2007; BOLLEYER; BÖRZEL, 2014; WATTS, 2006; BolLEYER; BöRZEL, 2014). A literatura aponta que acordos formais que coordenam parcerias interorganizacionais e definem responsabilidades dos atores envolvidos são centrais (POLLIT, 2003). Essas características podem afetar as escolhas sobre participar ou não da cooperação territorial, pois implica a criação de uma direção política comum, uma cultura de confiança, a solução conjunta de problemas e a negociação interorganizacional (BOGASON, 1998), que geram interdependência, compatibilidade e interação, fortalecendo o intercâmbio entre os participantes dos arranjos instituídos (ARIZNABARRETA, 2001).

As capacidades estatais também importam, pois cidades desprovidas de recursos organizacionais são menos prováveis de participar de consórcios, já que a ausência dessas capacidades aumenta os custos de transação do associativismo (CRAVACUORE; CLEMENTE, 2006; Grin; Abrucio, 2016; LUBell et al., 2002; Rodríguez-Oreggia; GUTIÉRREZ, 2006). Contudo, construir capacidade técnica, profissional e financeira para o consorciamento é um desafio-chave para as municipalidades (LACKEY; FRESHWATER; RUPASINGHA, 2002; BEL; WARner, 2016; BroWn; POTOSKI, 2003; Hefetz et al., 2012).

Quanto à liderança regional, duas questões são centrais: 1) formas de exercício e grau de dependência gerado pelo tipo de direção política adotada; 2) mecanismos formais e informais de coordenação entre os participantes. O papel do "líder territorial" e dos "empreendedores territoriais" ou de "políticas regionais" pode explicar a formação dos arranjos (ABRUCIO; SANO, 2013; ABRUCIO et al., 2010). 
A terceira dimensão refere-se aos mecanismos de indução (sustentabilidade financeira, fontes de recursos e divisão de pagamentos e regras federativas), que se constituem em prerrogativas de autonomia municipal para aderir ou não à cooperação territorial. Em federações, a variação nas regras nacionais das políticas setoriais que induzem o associativismo pode explicar diferentes tipos de arranjos (HULST; MONFORT, 2007, 2011; TAVARES; FEIOCK, 2018). Os incentivos das políticas nacionais variam entre os municípios, já que suas características locais, demandas territoriais comuns e porte populacional afetam suas escolhas (FEIOCK, 2007, 2009). O fluxo de recursos é vital para isso, assim como uma gestão financeira mais autônoma, pois viabiliza o associativismo e estimula a busca por fontes de recursos mais sustentáveis (DIEGUEZ, 2011; CALDAS; CHERUBINE, 2013). Com efeito, regras sobre como arrecadar recursos e dividir custos entre os participantes não são triviais para a implantação e a sustentabilidade do associativismo.

O Quadro 1 apresenta o modelo analítico proposto pelos autores a partir da sistematização da literatura sobre o tema.

\section{Quadro 1 | Modelo analítico}

\section{Dimensões}

1. Condições contextuais

Características regionais (diferenças socioeconômicas, de poder e de capacidade institucional entre os participantes)

Trajetória do arranjo

\section{Fatores endógenos}

2.1. Desenho institucional, processo decisório e modelo de governança

2.2 Natureza jurídica e suporte institucional e administrativo

2.3 Capacidades estatais dos municípios

2.4. Liderança regional

4. Mecanismos de indução

4.1 Fontes de financiamento

4.2 Regras federativas

Fonte: elaborado pelos autores. 


\section{Desenho da pesquisa e procedimentos metodológicos}

Esta é uma pesquisa comparada entre dois tipos de associativismo intermunicipal - consórcio público e ADE -, ambos situados no Estado de São Paulo e formados por municípios com variáveis demográficas e socioeconômicas semelhantes. Os dois modelos possuem um número de municípios maior e possuem uma vida associativa mais longa do que seus respectivos congêneres. Contudo, diferem na variável dependente, ou seja, no tipo de arranjo associativo, característica central que justifica a comparação dos casos selecionados.

O consórcio público intermunicipal é uma pessoa jurídica legalmente criada para exercer, por meio de contrato de rateio entre os municípios, a gestão associada de serviços públicos em que os participantes destinam pessoal, bens e recursos à execução dos serviços transferidos. Os ADEs são arranjos informais de colaboração territorial horizontal e intermunicipal, frequentemente conduzidos por organizações não governamentais, mediante convênios ou termos de cooperação, sem que exista a transferência de recursos públicos para estas organizações. São dois desenhos distintos de associativismo intermunicipal, considerando sua institucionalização legal e jurídica, o perfil de participantes e a existência e o tipo de financiamento (público nos consórcios, por meio da contribuição dos municípios participantes, e ausente ou privado nos ADEs, através do suporte de organizações que atuam na área de investimento social).

A pesquisa utiliza a técnica de análise do "caso mais similar" (most-similar case), que, conforme Gerring (2007), se baseia em casos parecidos em todos os aspectos, exceto a variável de interesse. O estudo inicia com uma aparente anomalia, já que os dois casos parecem similares, porém demonstram diferentes resultados; assim, busca-se identificar os fatores que os diferenciam, conforme sistematizado no Quadro 2.

\section{Quadro 2 | Gerando hipóteses (estudo de caso centrado na variável dependente)}

\begin{tabular}{|l|l|l|l|l|}
\hline & & $\mathrm{X} 1$ & $\mathrm{X} 2$ & $\mathrm{Y}$ \\
\hline & $\mathrm{A}$ & $?$ & 0 & 1 \\
\hline Estudos de caso & B & $?$ & 0 & 0 \\
\hline
\end{tabular}

Fonte: Gerring (2007, p. 132). 
Usualmente, a análise do "mais similar" visa compreender um relacionamento específico entre $\mathrm{X} 1$ e $\mathrm{Y}$, em que outros fatores causais comuns são mais ou menos constantes nos dois casos. Busca-se identificar os fatores subjacentes que explicam a relação entre a variável dependente $(Y)$ e as variáveis independentes (X1, X2 ...Xn) que distinguem os casos. Em função da utilização das mesmas variáveis independentes e da sua semelhança em ambos os casos, justifica-se a escolha do ADE Noroeste Paulista e o Civap neste estudo exploratório. A técnica utilizada suporta a discussão empírica, o cotejamento com a literatura e a proposição de um modelo analítico que permita gerar hipóteses explicativas para outras investigações.

Quanto aos instrumentos e técnicas de pesquisa, realizou-se: a) uma revisão bibliográfica; b) a análise de dados secundários, incluindo a caracterização socioeconômica e demográfica dos municípios; c) análise documental (relatórios, regimentos internos, planos de ação e materiais); d) seis entrevistas semiestruturadas de entre maio a junho de 2019. Foram entrevistados os seguintes atores: a) entrevistados 1 e 4 referem-se a representantes da direção política do consórcio (prefeitos de duas cidades que ocupam, respectivamente, os cargos de presidente e vice-presidente do Civap); b) entrevistado 5 foi ex-Secretária Municipal de Educação de um dos municípios participantes do ADE; c) gestores com responsabilidade técnica: entrevistados 2 e 3, gestores do Civp, e o entrevistado 5 do ADE. O objetivo das entrevistas foi preencher as lacunas encontradas na análise de dados secundários, assim como triangular os dados coletados, visando ampliar sua validade.

\section{O Consórcio Intermunicipal do Vale do Paranapanema}

A trajetória dos consórcios é longa no país, remonta à década de 1960, mas ganhou impulso após 1980 com o surgimento da assistência técnica e financeira do Governo Federal e governos estaduais e a atuação de entidades municipalistas (CRUz et al., 2011). Este é o caso do Civap, que foi criado em 1985 e impulsionado pela gestão Franco Montoro (1982-1986) a partir de uma visão de interiorização e reforço da ação municipal. 
O Civap tinha como foco principal o planejamento urbano regional para atender às demandas locais de forma articulada com os governos estadual e federal (Entrevista 1). Hoje possui 34 municípios e é um consórcio mulfinalitário focado no desenvolvimento socioeconômico regional, com ênfase em meio-ambiente, recursos hídricos, agricultura, educação, saneamento, tecnologia, habitação, infraestrutura, recursos humanos, turismo e saúde. É uma autarquia intermunicipal que integra a administração indireta das cidades consorciadas (Entrevista 4). Desde 2008, é um consórcio público, pois se avaliou que assim haveria maior transparência e eficácia para lidar com os problemas municipais (Entrevista 3), o que reforça o debate sobre a importância da institucionalização jurídica e legal dos arranjos (FEIOCK, 2007, 2013) apresentada no modelo analítico.

Quanto às variáveis contextuais, a Tabela 1 mostra que há diferenças no PIB per capita, percentual de população pobre, percentual de mães adolescentes e porte populacional, enquanto índices como Gini, IDHM e Ideb são mais convergentes. Assim como apontado por outros estudos, e a despeito 1. As entrevistas com a direção política e gerencial do Civap apontam que essas diferenças são menos determinantes para a existência do Consórcio em face da possibilidade de ganhos coletivos, sobretudo porque as cidades menores não têm porte suficiente para atuar mais autonomamente, o que reforça o associativismo.

Tabela 1 | Indicadores demográficos, financeiros e socioeconômicos dos municípios

\begin{tabular}{lccc}
\hline Variável & Valor mínimo & Valor máximo & $\begin{array}{c}\text { Média dos } \\
\text { municípios }\end{array}$ \\
\hline População (por mil hab.) & 839 & 102.924 & 14.852 \\
\hline PIB Municipal (R\$ milhões) & 30.917 & 2.855 .409 & 534.524 \\
\hline IDHM & 0,655 & 0,789 & 0,737 \\
\hline Índice de Gini & 0,36 & 0,55 & 0,46 \\
\hline \% População pobre & 0,85 & 23,26 & 6,71 \\
\hline Mortalidade infantil & 10,9 & 19 & 14,7 \\
\hline \% mães adolescentes & 0 & 6,44 & 2,64 \\
\hline IDEB Ensino Fundamental & 5 & 7,6 & 6,6
\end{tabular}

Fonte: elaborado pelos autores com base em Atlas do Desenvolvimento (PNUD, 2010), Censo da Educação Básica (Inep, 2017) e Contagem Populacional e PIB Municipal (IBGE, 2017). 
(1) Índice de Desenvolvimento Humano Municipal (IDHM): quanto mais próximo de 1 melhor.

(2) Índice de Gini: quanto mais próximo de 1 maior a desigualdade de renda

(3) Mortalidade infantil: número de óbitos de menores de um ano de idade, por mil nascidos vivos, em determinado espaço geográfico, no ano considerado.

Este caso mostra que não há evidências para afirmar que a homogeneidade socioeconômica e demográfica favorece o associativismo, como apontado por alguns estudos (FEIOCK, 2007; 2013; BAE; FEIOCK, 2012; FEIOCK; SCHOLZ, 2009). O mesmo vale para a afirmação de que maior heterogeneidade aumenta os custos de transação (BEL; Warner, 2016; FeIOck, 2007; Frug, 2001; LoWery, 2000; Post, 2002; Warner; Hefetz, 2002). Se assim fosse, a Câmara Técnica da Educação não lograria êxito, pois prevalece a ideia de que cooperação levará a uma redução ou partilha do custo da provisão de serviços (BEL et al., 2014).

Como a educação não possui uma lógica própria de associativismo, a Câmara Técnica da Educação, um órgão técnico vinculado ao consórcio, surgiu visando suprir carências financeiras, a falta de capacitação dos profissionais da área e de entrosamento entre as redes e a precária troca de informação entre as Secretarias Municipais (Entrevista 3).

A Câmara Técnica da Educação (Quadro 2), criada em 2015, é uma área interna na estrutura do Civap, já que a educação não costuma ser a política que lidera a formação de consórcios, que comumente se organiza posteriormente e considera os aprendizados de outras áreas (STRELEC, 2017). No Civap, as câmaras técnicas na saúde e meio ambiente foram as referências, produzindo um efeito de aprendizado sobre a área da educação. Um aspecto adicional foi a importância de atores externos - Itaú Social (financiador privado na área de investimento social) e Oficina Municipal (parceiro técnico) - para darem suporte inicial nesse processo (Entrevistas 2 e 4). 


\section{Quadro 2 | Objetivos principais do Câmara Técnica da Educação}

1. Oferecer embasamento técnico sobre educação regional e propor ações integradas.

2. Contribuir com a execução dos programas governamentais e atuar como um espaço de articulação, coordenação e acompanhamento educacional.

3. Reduzir deficiências dos órgãos gestores educacionais por meio do compartilhamento de experiências.

4. Subsidiar políticas públicas para o desenvolvimento da educação relativas ao ordenamento territorial, zoneamento agro-ecológico-econômico, erradicação das desigualdades e acesso à educação.

5. Diversificar atividades educacionais e sua articulação via parcerias dentro e fora do Civap.

6. Propiciar geração, apropriação e utilização de conhecimentos científicos, gerenciais e organizativos dos órgãos gestores educacionais.

7. Proporcionar a capacitação de profissionais da educação.

Fonte: Resolução no. 001, de 25 de junho de 2015.

A trajetória do Civap é essencial, pois mudanças no comando político-partidário nas prefeituras não têm afetado sua sustentabilidade ao longo do tempo (Entrevista 4). A literatura aponta que institucionalizar um arranjo organizacional produz maior estabilidade nas escolhas dos atores políticos, incentivando a sua existência (PIERSON, 2004; IMMERGUT, 1992), e esse é o caso do Civap Educação, como é chamada a Câmara Técnica que congrega os municípios ao redor dessa política pública. Portanto, a regularidade institucional foi seguida de mudanças incrementais (WEIR, 2006; HALL; TAYLOR, 2003) que resultaram na criação de um arranjo dentro da estrutura organizacional do consórcio, mas que seguiu o modelo de arranjos já conhecidos e existentes nela.

A Câmara Técnica da Educação uniformiza e reforça a ação em nível municipal, produzindo ganhos de escala com a capilaridade territorial das experiências (Entrevista 1 e 2). Por exemplo, o Guia do Atendimento Educacional Especializado foi criado para lidar com a falta de documentos legais sobre esse grupo de alunos e sistematizou meios para a coleta de informações, avaliação e diagnóstico deles. A organização de compras coletivas de material escolar, produtos de limpeza e veículos para o transporte estudantil também foi vantajosa para as cidades pequenas ao reduzir os preços unitários. Assim, a colaboração compensou deficiências técnicas e financeiras das localidades menores (Entrevista 4).

Também foram estabelecidos acordos para unificar calendário, currículos e alimentação escolar. Essa unificação buscava reduzir os impactos na aprendizagem de 
alunos cujas famílias mudam entre cidades vizinhas (Entrevista 2). Outra ação feita em colaboração é o acompanhamento da elaboração dos Planos Municipais de Educação, exigência decorrente do Plano Nacional de Educação (2014) (Entrevista 1 e 3). No entanto, essas mudanças não tiveram efeitos no Ideb dos anos iniciais do ensino fundamental (2005 a 2017). A nota cresceu de 4,86 para 6,44, mas não há como afirmar que se deva à Câmara Técnica da Educação, pois: a) essa área foi implantada em 2015; b) a média das notas dos vinte e dois municípios da região é similar ao crescimento dos demais municípios do estado. O mesmo pode ser dito da taxa de aprovação com seu aumento incremental de $2005(0,95)$ a $2015(0,98)$ (OFICINA MUNICIPAL, s/d).

Sobre o desenho institucional e o modelo de governança, a Câmara Técnica da Educação não possui personalidade jurídica, mas tem autonomia decisória, mesmo sendo subordinada à direção do Consórcio que é formada pelos prefeitos. A Câmara Técnica da Educação compõe-se da: a) Assembleia Geral integrada pelos gestores municipais; b) comissão executiva (membros se dividem em três polos regionais definidos pela Assembleia, sendo que cada polo escolhe dois coordenadores que formam a Comissão Executiva e são designados pelo presidente do Consórcio); c) secretaria executiva (um gestor municipal eleito pelos pares); d) coordenador e vice- coordenador eleitos pelos pares (com direito a recondução); e) comissão de ética. Com efeito, o desenho institucional influencia a forma como se implementa a cooperação intergovernamental (KLOK et al., 2018; HULST; MONFORT, 2007).

A estrutura organizacional mostra um arranjo de governança com capacidade de comando e coordenação que serve de base à gestão assentada em atributos de capacidade técnica e cooperação (Bel; WARner, 2016; BroWn; POTOSKI, 2003; HefETZ et al., 2012). A escolha dos dirigentes da Câmara Técnica da Educação por aclamação baseia-se na negociação interorganizacional (BOGASON, 1998), parceria interorganizacional (POLLIT, 2003) e ajustamentos mútuos para gerar interação entre as cidades sob um marco comum de intercâmbio (ARIZnABARRETA, 2001).

A Câmara Técnica da Educação conta com apoio jurídico, financeiro, logístico e da equipe de licitação do Consórcio (Entrevista 3). A secretaria executiva é central para gerar economia de tempo e de recursos financeiros ao assumir a gestão cotidiana e também para reduzir a necessidade de consulta aos gestores municipais (Entrevista 4). O peso do 
voto municipal é igual, mas as decisões são adotadas principalmente de forma consensual (Entrevista 4). Assim, cada cidade preserva sua autonomia e respeitam-se particularidades em relação à integração ou não de suas atividades, pois cada novo projeto requer investimentos proporcionais ao número de participantes (Entrevista 2), e os valores de contribuição são proporcionais às suas populações.

Para os entrevistados, há convicção de que a Câmara Técnica da Educação ampliou o protagonismo e a liderança coletiva dos gestores educacionais que souberam desfrutar da autonomia conferida pela direção do consórcio (Entrevista 3). A confiança, mencionada pela literatura (DI PORTO; PATY, 2018), gerou uma curva de aprendizado nas secretarias municipais de educação, pois os prefeitos que lideram o consórcio vêm delegando a condução da gestão educacional aos secretários de educação. Eles se "empoderaram e perceberam que são atores tão chave como os prefeitos, ainda que não tenham poder de veto e de voto (Entrevistado 2). Houve, segundo um dos entrevistados, a desvinculação com a "parte política", enfatizando-se questões técnicas, e ampliaram a confiança entre os participantes (Entrevista 3), fortalecendo a liderança educacional regionalmente (ABRUCIO; SANO, 2013; ABRUCIO et al., 2010) a partir da coordenação.

Um dos maiores receios é que a interferência política venha a causar descontinuidade administrativa e técnica, mas há consenso de que a Câmara Técnica da Educação é um "núcleo blindado quanto à questão partidária". O contencioso político fica de fora, pois o foco são temas de natureza técnica, incluindo o compartilhamento de experiências (Entrevistas 1, 3 e 4). Isso porque o papel da secretaria executiva é vital para separar a política da gestão e a diretoria administrativa da Câmara Técnica da Educação também é um anteparo que busca preservar essa separação (Entrevista 3).

A governança da Câmara Técnica da Educação ainda não possui um processo definido de planejamento com metas e prazos e, portanto, atua mais segundo demandas com as quais necessita lidar em face de suas atribuições (Entrevistas 3 e 4). Existem instrumentos de transparência e prestação de contas: há duas audiências anuais, as decisões são enviadas às prefeituras consorciadas e a prestação de contas, à assembleia do consórcio. Todavia, seu sítio na internet não disponibiliza informações sobre a educação, o que dificulta o seu acesso pelo cidadão. 
Sobre as capacidades estatais municipais, a Tabela 2 mostra os indicadores financeiros, administrativos e educacionais.

Tabela 2 | Indicadores de capacidade estatal

\begin{tabular}{|c|c|c|c|c|}
\hline Variável & $\begin{array}{l}\text { Valor } \\
\text { mínimo }\end{array}$ & $\begin{array}{l}\text { Valor } \\
\text { máximo }\end{array}$ & $\begin{array}{l}\text { Média dos } \\
\text { municípios }\end{array}$ & $\begin{array}{l}\text { Média } \\
\text { estadual }\end{array}$ \\
\hline \% Arrecadação própria & 6,4 & 57,6 & 22,53 & 37,5 \\
\hline $\begin{array}{l}\text { № de servidores municipais } \\
\text { por habitante }\end{array}$ & 6,8 & 48,9 & 21,3 & 47,9 \\
\hline $\begin{array}{l}\text { \% Servidores com ensino } \\
\text { superior ou pós-graduação }\end{array}$ & 3,7 & 56,1 & 35,5 & 45 \\
\hline $\begin{array}{l}\text { № de servidores municipais } \\
\text { na área da educação }\end{array}$ & 5 & 1892 & 353 & 1329,4 \\
\hline № de professores municipais & 4 & 267 & 42,8 & 158 \\
\hline $\begin{array}{l}\% \text { Plano de carreira } \\
\text { magistério }\end{array}$ & 0 & 1 & 94 & 91,3 \\
\hline \% Secretaria exclusiva da área & 0 & 1 & 47 & 69,7 \\
\hline $\begin{array}{l}\text { \% gestão financeira dos } \\
\text { recursos pela área da } \\
\text { educação }\end{array}$ & 0 & 1 & 35,3 & 39,1 \\
\hline \multicolumn{5}{|c|}{ Fonte: elaborado pelos autores com base em Índice Firjan de Gestão Fiscal (2017) e Munic IBGE (2014 e 2017). } \\
\hline
\end{tabular}

A literatura aponta que as capacidades estatais importam, pois as cidades com menores recursos de gestão são menos prováveis de participarem de consórcios (Cravacuore; Clemente, 2006; Grin; Abrucio, 2016; Lubell et al., 2002; RodríguezOREGGIA; TUIRÁN, 2006), mas construir capacidade técnica e financeira é um desafio (LACKey et al., 2002; BEL; WARneR, 2016; BROWN; Potoski, 2003; HefETZ et al., 2012). No entanto, a Câmara Técnica da Educação não oferece suporte empírico para confirmar essa hipótese, conforme os indicadores da Tabela 2. Além da disparidade municipal, as localidades distam da média estadual (exceto no Plano de Carreira do Magistério). Isso mostra que o êxito do consórcio nessas três décadas parece estar relacionado aos custos da 
ação coletiva, que são menores do que os benefícios gerados, apesar da heterogeneidade municipal dos associados.

Sobre os mecanismos de financiamento, as cidades contribuem com valores fixos e valores per capita, conforme definido no contrato de rateio, que garante acesso a serviços como licitações coletivas. E quando são realizados projetos específicos de capacitação, os municípios que participam pagam valores per capita (entrevista 2 e 3). Como a situação socioeconômica municipal é similar, disputas sobre critérios de contribuição (Entrevista 4) e problemas de heterogeneidade que poderiam implicar no afastamento ou na não participação de algumas prefeituras não são relevantes.

O ponto frágil do financiamento é a pouca participação da iniciativa privada, que segue como um desafio a ser superado (Entrevista 4), mas há mecanismos de financiamento que garantem a sustentabilidade, ao mesmo tempo que induzem a participação municipal sem ferir sua autonomia, além de gerar capacidade de gestão e fluxo de recursos (CALDAS; Cherubine, 2013; Dieguez, 2011). Sobre isso, nos três anos iniciais (2015-2017), o Itaú Social "incubou" e financiou a Câmara Técnica da Educação (Entrevistas 3 e 4), o que mostra a relevância do suporte externo.

Toda cidade que decide participar de formações deve ser associada ao Civap. Objetiva-se, assim, não enfraquecer os vínculos coletivos e estimular comportamentos oportunistas e free riders que não estão interessados nas responsabilidades de participarem do consórcio. Mesmo havendo uma unanimidade entre os prefeitos sobre a importância da Câmara Técnica da Educação, ainda é um desafio convencer os novos secretários municipais a continuarem ou aderirem ao consórcio (Entrevistas 3 e 4).

Em relação à indução federal e estadual que induz ao associativismo e pode explicar variações nos arranjos (HULST; MONFORT, 2007, 2011; TAVARES; FEIOCK, 2018), não há evidências de que esses estímulos sejam uma condição necessária, pois a trajetória do Civap indica que as escolhas municipais autônomas e voluntárias têm sido suficientes para a adesão e sustentabilidade do consórcio. 


\section{O arranjo de desenvolvimento da educação do noroeste paulista}

Os primeiros ADEs surgiram em 2009, a partir da iniciativa de atores estatais e não estatais. Em agosto desse ano foi criado o ADE do Recôncavo Baiano a partir da articulação entre o Ministério da Educação, a Secretaria de Educação da Bahia, a União Nacional de Dirigentes da Educação na Bahia, o Conselho Estadual de Educação, o Instituto Votorantim, o Todos pela Educação ${ }^{1}$, as Secretarias Municipais de Educação e a Universidade do Recôncavo Baiano (RAMOs; ABRUCIO, 2012; CRUz, 2014). Apesar de ter sido a experiência pioneira, esse ADE não teve continuidade (CRUZ, 2014).

Ainda em 2009, outros três ADEs foram criados: Linha Férrea de Carajás (Maranhão), Noroeste Paulista (São Paulo) e Agreste Meridional de Pernambuco. Os ADEs se disseminaram no país: com a criação de 11 até o início de 2012, o número total subiu para 15, embora alguns já estejam desativados (ABRUCIO, 2017; CRUZ, 2014). Esses ADEs começaram com uma articulação entre 15, 17 e 23 municípios, respectivamente, mas incorporaram outros nos anos seguintes. O ADE Noroeste Paulista foi o caso que incorporou um número maior de municípios e, atualmente, é formado por 65 municípios.

No que se refere aos indicadores demográficos, financeiros e socioeconômicos, a Tabela 3 mostra que variam mais do que no Civap. Contudo, como será discutido, os entrevistados não mencionaram essas diferenças como relevantes para a opção pelo $A D E$, tal como apontado pela literatura.

\footnotetext{
${ }^{1}$ Organização da sociedade civil, sem fins lucrativos e suprapartidária, cujo objetivo central é impulsionar a qualidade e a equidade da educação básica no país.
} 
Tabela 3 | Indicadores demográficos, financeiros e socioeconômicos dos municípios

\begin{tabular}{l|c|c|c}
\hline Variável & Valor mínimo & Valor Máximo & Média dos municípios \\
\hline População (por mil hab.) & 1.239 & 92.768 & 10.412 \\
\hline PIB Municipal (R\$ milhões) & 30.390 & 2.680 .060 & 316.051 \\
\hline IDHM & 0,664 & 0,819 & 0,741 \\
\hline Índice de Gini & 0,33 & 0,76 & 0,462 \\
\hline \% População pobre & 0,38 & 25,07 & 5,28 \\
\hline Mortalidade infantil & 0,45 & 31,9 & 14,33 \\
\hline \% Mães adolescentes & 0 & 16,7 & 3,02 \\
\hline IDEB Ensino Fundamental I & 5,8 & 8,2 & 6,83 \\
\hline
\end{tabular}

Fonte: elaborado pelos autores com base em Atlas do Desenvolvimento (PNUD) (2010), Censo da Educação Básica (Inep) (2017) e Contagem Populacional e PIB Municipal (IBGE) (2017)

(4) IDHM: quanto mais próximo de 1, melhor.

(5) Índice de Gini: quanto mais próximo de 1, maior a desigualdade de renda.

(6) Mortalidade infantil: número de óbitos de menores de um ano de idade, por 1 mil nascidos vivos, em determinado espaço geográfico, no ano considerado.

Os ADEs são formados pela articulação realizada por organizações privadas da sociedade civil, inicialmente, com a Comunidade Educativa Cedac, a Fundação Vale e o Todos pela Educação e, ao longo do tempo, envolveram-se outras organizações, como Instituto Natura e Itaú Social. No ADE Noroeste Paulista, os entrevistados (5 e 6) relataram que a liderança do Prefeito de Votuporanga (2009-2016), Nasser Marão Filho, foi essencial. Mozart Ramos, então representante do Todos pela Educação, foi o influenciador dos ADEs como solução para abordar problemas regionais comuns (ABRUCIO; SOARES, 2001; Grin; SegATto; ABRUCIO, 2016; LACZYNSKI, 2012), desempenhando a função de um "empreendedor".

O prefeito e a secretária municipal de educação de Votuporanga conseguiram a adesão ao ADE de 17 incumbentes dos municípios vizinhos. Em seguida, foi constituído o Centro de Liderança Pública visando institucionalizar esse arranjo, em linha com os argumentos da literatura (RAMOS; ABRUCIO, 2012; IMMERGUT, 1992; HALL; TAYLOR, 2003; PIERSON, 2004). A secretária e a sua equipe desenvolveram um modelo de gestão em redes a partir da sua experiência profissional no Senac, instituição onde havia trabalhado com essa metodologia. 
Baseadas nessa experiência, em 2010, surgiram iniciativas para institucionalizar os ADEs, como o projeto de lei do deputado Alex Canziani e a criação da Comissão de Estudos para Parecer e Resolução pelo Conselho Nacional de Educação. Ademais, organizações como o Instituto Natura começaram a articular representantes dos ADEs (RAMOS; ABRUCIO, 2012). Em 2011, a Secretaria de Articulação de Sistemas de Ensino (Sase) do MEC foi criada para atuar no campo da cooperação intermunicipal na educação, e um grupo de trabalho foi instalado para, além de debater o tema, apoiar a implantação de um ADE com os municípios da Região do Xingu. A experiência buscou melhorar a organização das ações governamentais, diminuir os impactos ambientais e compreender como os arranjos se estruturavam, bem como seus resultados (CRUZ, 2014).

O Conselho Nacional de Educação formulou um parecer para que os ADEs orientassem suas ações para a formulação do Plano de Ações Articuladas (PAR) em quatro dimensões: gestão educacional, formação de professores e dos profissionais de serviço e apoio escolar, práticas pedagógicas e avaliação, infraestrutura física e recursos pedagógicos. ${ }^{2}$ Esse parecer também determinou que os arranjos fossem administrados por um gestor apoiado por um Conselho de Gestão Intergovernamental (CONSELHO NACIONAL DA EdUCAÇÃO, 2011).

Apesar desses avanços, diferentemente dos consórcios públicos, inexiste legislação regulamentando os $A D E s$, o que fragiliza sua segurança institucional e dificulta sua expansão, reforçando os argumentos da literatura sobre a importância dessa dimensão na formação e continuidade dos arranjos (HULST, MONFORT, 2007, 2011; TAVARES; FEIOCK, 2018). Também não há incentivos financeiros dos governos federal e estadual que induzam a criação dos ADEs. No ADE Noroeste Paulista, para os entrevistados (5 e 6), a influência de Mozart Ramos foi fundamental para disseminar esse arranjo. Os entrevistados destacaram que os municípios compartilhavam uma preocupação quanto à falta de informação e dificuldades para elaborarem o PAR e aderirem a programas federais. Além disso, para os entrevistados (5 e 6), por ser uma região distante dos polos regionais, há maior dificuldade em participar de formações que ocorrem nos municípios maiores como São Paulo.

\footnotetext{
${ }^{2}$ O PAR é uma estratégia de assistência técnica e financeira iniciada pelo Plano de Metas Compromisso Todos pela Educação
} de 2007. O MEC oferece aos municípios instrumentos de diagnóstico e planejamento educacional. 
Nesse momento inicial, o "empreendedor" Mozart Ramos e a Sase/MEC assessoraram os municípios na identificação das suas necessidades comuns utilizando o PAR como recurso (ABRUcio, 2017; PereIRA, 2014). Segundo o entrevistado 5, o PAR foi central porque "o diagnóstico dos municípios estava lá". A partir disso, as ações do arranjo se concentraram em formações de dois tipos: a) para as equipes das secretarias municipais de educação sobre o PAR e os programas federais; b) para as equipes de gestão das escolas e os professores sobre temas relacionados às suas atividades administrativas e pedagógicas (Entrevistas 5 e 6).

Sobre a capacitação para o PAR e os programas federais, os gestores de algumas secretarias tinham mais conhecimento do que outros (Entrevista 6). Inicialmente, essas atividades de formação, ao assessorarem os municípios, operavam como um mecanismo de troca de experiência entre todos. Gestores do MEC e especialistas eram responsáveis por essas formações, incluindo a gestora responsável pelo Mais Educação, que fez um acordo com os municípios para que pudessem acessar esse Programa. ${ }^{3}$ Para os entrevistados, o ADE é um espaço importante para a troca de experiências entre as secretarias, especialmente para aqueles que iniciam suas gestões sem experiência profissional anterior nas redes municipais de ensino. Isso porque boa parte dos secretários e equipes não tem experiência e/ou conhecimentos em gestão (PEREIRA, 2014).

Nos anos seguintes, o ADE passou a compreender outros temas relevantes derivados das reuniões entre os gestores municipais de educação. Ainda, o ADE participou de um Laboratório de Mudança, apoiado pelo Instituto Natura, voltado para a formação de gestores escolares e para fortalecer suas competências de liderança; participou de uma rede de colaboração intermunicipal de educação, coordenada pela Sase, juntamente com representantes de outros ADEs, consórcios e organizações parceiras da sociedade; mais recentemente, tem participado de uma rede apoiada pelo Itaú Social.

Em relação à organização e à governança do arranjo, os entrevistados apontam que se adotou o modelo de redes, caracterizado pela mediação, construção de consensos e horizontalidade nas decisões compartilhadas entre os participantes. O ADE "[...] tem

\footnotetext{
${ }^{3}$ Estratégia do Ministério da Educação para indução da educação integral nas redes estaduais e municipais de ensino que amplia a jornada escolar nas escolas públicas para, no mínimo, sete horas diárias.
} 
como finalidade direcionar as ações do arranjo e fortalecer o compromisso firmado com o grupo" (BATISTA, 2018, p. 12). Para aderir ao arranjo, um município deve estar localizado no Noroeste do Estado de São Paulo, ter aderido ao PAR e os prefeitos devem assinar uma carta de compromisso e princípios. A adesão ao ADE é simples se comparada às exigências de associação a um consórcio. Segundo relatado pelos entrevistados (5 e 6), regras mais rígidas seriam um entrave ao associativismo, pois os municípios podem entrar e sair sem maiores ônus. A importância da horizontalidade reforça os argumentos apontados pela literatura (BOLLEYER; BÖRZEL, 2014; KLOK et al., 2018; HULST; MONFORT, 2007), mas os efeitos positivos da falta de institucionalização não são defendidos pela literatura.

Na estrutura do $A D E$, há uma plenária, uma coordenação executiva que inclui servidores e secretários municipais e comissões de trabalho (PEREIRA, 2014). Assim, para Abrucio (2017):

O papel da Coordenação Executiva é zelar pelo engajamento do Grupo Gestor; abaixo há o Grupo Gestor, composto pela equipe técnica das secretarias, formado a partir de eleições democráticas, sendo ele o responsável por fomentar no coletivo as questões que têm que ser discutidas e as tomadas de decisões. Na governança há também a guia da Secretaria Executiva, que operacionaliza o ADE. Além disso, há uma Coordenação de Grupos, posição nova surgida na última gestão do Arranjo (ABRUCIO, 2017, p. 124-125).

Não há uma estrutura administrativa com cargos e salários, tampouco presidente do arranjo e hierarquia organizacional, de modo que as coordenações e grupos buscam compensar essa fragilidade institucional. Trata-se de uma gestão baseada na negociação interorganizacional (BOGASON, 1998), em esforços de parceria interorganizacional (Pollit, 2003) e em ajustamentos mútuos (ARIZnABARRETA, 2001). Busca-se preservar a horizontalidade para que "todos os municípios, independentemente do tamanho, possam ter poder igual de voto" (ABRUCIO, 2017, p. 124). Entretanto, é desafiador manter a horizontalidade na tomada de decisão com o aumento do número de municípios membros. Também não há uma pessoa jurídica, orçamento e servidores próprios, o que também poderia ser um desincentivo ao associativismo (CALDAS; Cherubine, 2013; Dieguez, 2011). 
Para que esse arranjo implemente suas ações, os entrevistados (5 e 6) apontam que a liderança informal da secretaria de educação do município de Votuporanga, que alocou um servidor para responder pelas suas atividades, é fundamental. Os entrevistados (5 e 6) apontam que as iniciativas sem custos são priorizadas; mas, caso existam custos, os municípios pagam e dividem entre si. O ADE possui parcerias com outras instituições, como a Associação de Municípios da Araraquarense, que é uma pessoa jurídica, e o Senac, o Instituto Federal e o Centro Universitário de Votuporanga, que cedem espaços físicos e equipamentos, por exemplo, para viabilizar suas atividades. A União de Dirigentes Municipais de Educação (Undime) também foi mencionada como um importante parceiro para apoiar o relacionamento com os municípios e realizar as formações.

Conforme os entrevistados (5 e 6), esses são os benefícios do ADE, ou seja, maior horizontalidade no processo decisório e flexibilidade para a sua formação, na tomada de decisão e na entrada e saída de novos membros. O consórcio público foi considerado um modelo que exigiria uma maior institucionalização na coordenação municipal, o que dificultaria a cooperação entre os municípios. Porém, o consórcio permitiria expandir as ações de cooperação, incluindo a realização de processos de seleção de docentes em conjunto. Além desse desafio, a efetivação da participação dos municípios e o envolvimento dos governos federal e estadual também foram mencionados por um dos entrevistados (Entrevistado 6).

Em relação à capacidade estatal municipal, os indicadores financeiros e administrativos (Tabela 4 e Entrevistas 5 e 6) mostram que, apesar da diversidade entre os municípios, esses não são fatores definidores do compartilhamento de custos. 
Tabela 4 | Indicadores de capacidade estatal

\begin{tabular}{|c|c|c|c|c|}
\hline Variável & $\begin{array}{l}\text { Valor } \\
\text { mínimo }\end{array}$ & $\begin{array}{l}\text { Valor } \\
\text { máximo }\end{array}$ & $\begin{array}{l}\text { Média dos } \\
\text { municípios }\end{array}$ & $\begin{array}{c}\text { Média } \\
\text { estadual }\end{array}$ \\
\hline \% Arrecadação própria & 5 & 100 & 24,8 & 37,5 \\
\hline $\begin{array}{l}\text { № de servidores municipais } \\
\text { por habitante }\end{array}$ & 8,5 & 52 & 20,6 & 47,9 \\
\hline $\begin{array}{l}\text { \% Servidores com ensino superior ou pós- } \\
\text { graduação }\end{array}$ & 3,7 & 56,1 & 36,7 & 45 \\
\hline $\begin{array}{l}\text { № de servidores municipais na área da } \\
\text { educação }\end{array}$ & 19 & 1590 & 268 & 1329,4 \\
\hline № de professores municipais & 3 & 235 & 23,9 & 158 \\
\hline Plano de Carreira magistério & 0 & 1 & 89,3 & 91,3 \\
\hline Secretaria exclusiva da área & 0 & 1 & 56 & 69,7 \\
\hline $\begin{array}{l}\text { Gestão financeira dos recursos pela área } \\
\text { da educação }\end{array}$ & 0 & 1 & 18,3 & 39,1 \\
\hline \multicolumn{5}{|c|}{ Fonte: elaborado pelos autores com base em Índice Firjan de Gestão Fiscal (2016) e Munic IBGE 2014 e 2017.} \\
\hline \multicolumn{5}{|c|}{ (5) Servidores municipais: estatutários, celetistas e comissionados (exceto estagiários/sem vínculo permanente). } \\
\hline \multicolumn{5}{|c|}{ (6) Número de professores total (ensino infantil, fundamental e ensino médio). } \\
\hline \multicolumn{5}{|c|}{ (7) Escolaridade de servidores: somente: aqueles com graduação ou pós-graduação. } \\
\hline
\end{tabular}

Contudo, para os entrevistados (5 e 6), a construção de capacidades administrativas nas secretarias, o assessoramento, a troca de experiências e aprendizagem entre gestores e dirigentes educacionais foram os fatores que orientaram sua escolha para participar do ADE. Isso reforça as conclusões de Abrucio (2017), que aponta que o ADE ampliou o engajamento dos secretários, gestores e professores. No entanto, atribui-se ao arranjo o aumento do Ideb dos municípios participantes (ABRUcio, 2017; BATISTA, 2018). Assim, para Batista (2018):

Em 2009, quando o Arranjo foi criado, o Ideb médio dos anos iniciais na região era 6,0; já nos resultados referentes a 2017 o índice passou a 6,7. Além disso, a discrepância entre o menor e maior resultado ficou menor, passando de 2.9 para 2,0, indicando nivelamento positivo entre os municípios (BATISTA, 2018, p. 16).

Esses resultados positivos chamam a atenção dos municípios vizinhos e levam os participantes a continuarem no arranjo. 


\section{Conclusão}

A análise dos casos mostra que há semelhanças e diferenças quanto às escolhas municipais sobre participar de um consórcio ou de um ADE. Nos dois casos, diferenças socioeconômicas e de capacidade institucional municipal não são relevantes. Todavia, a trajetória e o aprendizado institucional os distinguem, pois a Câmara Técnica da Educação resultou da experiência dos congêneres na saúde e no meio ambiente. Assim, retornos crescentes de colaboração regional influenciaram os novos formatos de cooperação. Ademais, a estabilidade institucional propiciada pela legislação e a continuidade do consórcio geraram confiança para constituir a Câmara Técnica de Educação. Nesse sentido, a sustentabilidade da experiência e o aprendizado institucional foram condições contextuais fundamentais.

Os dirigentes do Civap creem que uma variável decisiva para a escolha do tipo de associativismo é de cunho político: quando prevalece o "autarquismo municipal" (DANIEL, 2001) ou a competição partidária, há obstáculos para uma cooperação intermunicipal mais ampla (Entrevistas 1 e 3 ).

Quanto à dimensão do desenho institucional e modelo de governança, a razão central que diferencia a escolha é o grau de formalização, isto é, a criação de uma pessoa jurídica, a existência de orçamento e de um corpo de funcionários próprios que geram segurança jurídica e a estabilidade institucional. No caso do ADE, o seu funcionamento como rede horizontal de relacionamento e troca de experiências intermunicipais permite maior flexibilidade e explicar a sua continuidade, pois suas decisões são menos vinculatórias, o que diminui as barreiras de entrada e de saída de municípios, ainda que a cooperação seja mais restrita e inexista suporte legal para as ações conjuntas.

As disparidades de capacidades estatais não explicam os porquês da opção por um dos modelos, pois sua heterogeneidade regional não influenciou a escolha do tipo de arranjo associativo. No entanto, nos dois modelos, secretários municipais de educação são centrais para liderarem uma gestão mais autônoma das ações, embora distintamente limitados: no ADE, pelo financiamento externo, e no Civap, pela direção política dos prefeitos. Além disso, ainda que a diferença nas capacidades não tenha influenciado sua 
formação e adesão de novos municípios ao ADE, Votuporanga lidera a implementação das ações, o que influencia a sua continuidade.

No caso do $A D E$, um empreendedor externo liderou esse processo, algo comum a outras experiências similares induzidas ou apoiadas por organizações da sociedade civil, sobretudo institutos e fundações empresariais atuantes na política educacional. No Civap, sua institucionalização em mais de 30 anos, a despeito da competição partidária municipal e regional, não evidencia a importância desse tipo de liderança.

A indução federativa dos níveis superiores de governo não é relevante, de forma que a autonomia municipal para aderir aos arranjos fica preservada e assume maior relevância. A maior distinção reside na sustentabilidade financeira, pois o contrato de rateio municipal é a base para manter a Câmara Técnica da Educação, sendo marginal o apoio privado. No ADE, as ações conjuntas ficam restritas em função da inexistência de um orçamento próprio e são dependentes, em grande medida, do suporte privado das fundações empresariais atuantes na política educacional.

Considerando os casos analisados, os fatores explicativos comuns para a escolha por um consórcio ou um ADE na educação envolveram mais fatores endógenos, incluindo a natureza jurídica do modelo, o modelo de governança e o processo decisório. A influência da liderança regional variou entre os casos, assim como as condições contextuais relacionadas, principalmente a trajetória (aprendizado e confiança institucional),enquanto a liderança teve um papel mais importante no ADE por ser um caso mais recente, em que a atuação dos atores foi mais importante para a formação e consolidação do arranjo. As condições contextuais influenciaram mais fortemente o caso da Câmara Técnica da Educação, que foi resultado de uma trajetória bem sucedida de cooperação.

O Quadro 3 sintetiza os principais achados em relação às similaridades e diferenças nos dois formatos institucionais de associativismo intermunicipal educacional. Sendo esse um estudo de caso exploratório, as dimensões e variáveis empíricas no Quadro 3, além de compararem os dois casos analisados, também visam embasar hipóteses para novas investigações que testem sua capacidade explicativa. 


\section{Quadro 3 | Semelhanças e diferenças nos modelos de associativismo: dimensões e variáveis de interesse}

\begin{tabular}{|c|c|c|}
\hline \multicolumn{3}{|c|}{ Variáveis de interesse } \\
\hline Dimensões & Consórcio público & ADE \\
\hline Políticos & $\begin{array}{l}\text { 1.1 Maior visibilidade e representatividade } \\
\text { regional dos municípios. } \\
\text { 1.2 Reforça a ação coletiva junto aos } \\
\text { governos estadual e federal. } \\
1.3 \text { Integração regional. } \\
\text { 1.4 Garantia de apoio continuado, ao longo } \\
\text { do tempo, dos prefeitos de todos os partidos. }\end{array}$ & $\begin{array}{l}\text { 1.1 Maior visibilidade e } \\
\text { representatividade regional } \\
\text { dos municípios. } \\
\text { 1.2 Reforça a ação coletiva } \\
\text { junto aos governos estadual } \\
\text { e federal. } \\
1.3 \text { Integração regional. }\end{array}$ \\
\hline Econômicos & $\begin{array}{l}\text { 2.1 Divisão de custos e ampliação dos } \\
\text { recursos disponíveis coletivamente para as } \\
\text { cidades. } \\
\text { 2.2 Ganhos de escala nas compras realizadas, } \\
\text { sobretudo para as pequenas cidades. } \\
\text { 2.3 Possibilidade de realizar convênios e } \\
\text { parcerias para captar recursos privados e } \\
\text { públicos. } \\
\text { 2.4 Faculta a prestação de serviços. }\end{array}$ & $\begin{array}{l}2.1 \text { Ganhos de escala nas } \\
\text { ações realizadas. } \\
\text { 2.2 Possibilidade de realizar } \\
\text { parcerias para captar } \\
\text { recursos com patrocinadores } \\
\text { privados e públicos. }\end{array}$ \\
\hline $\begin{array}{l}\text { Jurídico- } \\
\text { administrativos }\end{array}$ & $\begin{array}{l}\text { 3.1 Possibilidade de conveniar e contratar } \\
\text { serviços com outras entidades. } \\
\text { 3.2 Permite a realização de licitações } \\
\text { consorciadas. } \\
\text { 3.3 Permite realizar contratos com entes } \\
\text { públicos e privados. }\end{array}$ & $\begin{array}{l}\text { 3.1 Maior liberdade e } \\
\text { flexibilidade de ação sem a } \\
\text { personalidade jurídica. }\end{array}$ \\
\hline Organizacionais & $\begin{array}{l}\text { 4.1 Unificação dos calendários escolares das } \\
\text { cidades. } \\
\text { 4.2 Maior acesso às Câmaras Técnicas } \\
\text { (educação, saúde e meio-ambiente) e a } \\
\text { projetos compartilhados. } \\
\text { 4.3 Reduz a carga das tarefas burocráticas } \\
\text { nas cidades, pois o consórcio assume as } \\
\text { atividades-meio. } \\
\text { 4.4 Acesso facilitado às informações úteis } \\
\text { para o funcionamento das Secretarias } \\
\text { Municipais e redes escolares. } \\
\text { 4.5 Qualifica o foco do gestor educacional na } \\
\text { área pedagógica. } \\
4.6 \text { Desenvolve conhecimento em redes } \\
\text { colaborativas e cultura de cooperação. }\end{array}$ & $\begin{array}{l}\text { 4.1 Qualifica o foco do } \\
\text { gestor educacional na área } \\
\text { pedagógica. } \\
\text { 4.2 Desenvolve conhecimento } \\
\text { em redes colaborativas e } \\
\text { cultura de cooperação. }\end{array}$ \\
\hline
\end{tabular}


Variáveis de interesse

\begin{tabular}{|l|l|l} 
Dimensões & Consórcio público & ADE \\
\hline Técnicos & $\begin{array}{l}\text { 5.1 Capacitação de gestores educacionais e } \\
\text { servidores escolares. }\end{array}$ & $\begin{array}{l}\text { 5.1 Capacitação de gestores } \\
\text { educacionais e servidores } \\
\text { escolares. }\end{array}$ \\
\hline $\begin{array}{ll}\text { 5.2 Melhora dos protocolos de cardápio da } \\
\text { alimentação escolar e redução de custos. } \\
\text { 5.3 Compartilhamento de experiências entre } \\
\text { as redes de ensino e aprendizado mútuo } \\
\text { continuado e sustentável. }\end{array}$ & $\begin{array}{l}\text { 5.2 Compartilhamento de } \\
\text { experiências entre as redes } \\
\text { de ensino e aprendizado } \\
\text { mútuo continuado e } \\
\text { 5.4 Viabiliza atendimento técnico } \\
\text { especializado para os municípios associados. }\end{array}$ & $\begin{array}{l}\text { s.4 Viabiliza atendimento } \\
\text { técnico especializado para os } \\
\text { municípios associados. }\end{array}$ \\
\hline
\end{tabular}

Fonte: elaborado pelos autores conforme entrevistas 1, 2, 3, 4, 5 e 6.

Como se espera de estudos de caso, este artigo analisa duas experiências que embasam hipóteses e argumentos que podem servir de referência para outras pesquisas. Espera-se que este estudo possa contribuir com um duplo objetivo: gerar conhecimento sobre o associativismo territorial entre municípios brasileiros na educação e propor um modelo analítico para novos estudos sobre cooperação intermunicipal nessa política.

\section{Referências}

ABRUCIO, Fernando L. Cooperação Intermunicipal: experiências de Arranjos de Desenvolvimento da Educação no Brasil. Curitiba: Instituto Positivo. 2017.

ABRUCIO, Fernando L.; SANO, Hironobu. Associativismo Intergovernamental: experiências brasileiras. Brasília: Fundação Instituto para o Fortalecimento das Capacidades Institucionais/ Agência Espanhola de Cooperação Internacional para o Desenvolvimento/Ministério do Planejamento, Orçamento e Gestão/Editora IABS. 2013.

ABRUCIO, Fernando L.; SANO, Hironobu; SYDOW, Christina. Radiografia do associativismo territorial brasileiro: tendências, desafios e impactos sobre as regiões metropolitanas. In: MAGALHÃES, Fernanda. Regiões metropolitanas no Brasil. Washington: BID, 2010. p. 197-234.

ABRUCIO, Fernando L.; SOARES, Marcia M. Redes federativas no Brasil: cooperação intermunicipal no grande $A B C$. São Paulo: Fundação Konrad Adenauer. 2001.

AgRANOFF, Robert. Intergovernmental Policy Management: cooperative practices in federal systems. In: PAGANO, Michael A.; LeONARDI, R. The dynamics of federalism in national and supranational political systems. New York: Palgrave Macmillian, 2007, p. 248-284.

AgRANOFF, Robert. Managing within the Matrix: do collaborative intergovernmental relations exist? Publius: The Journal of Federalism, v. 31, n. 2, p. 31-56, 2001. 
ARIZNABARRETA, Koldo E. Capital social, cultura organizativa y transversalidad en la gestión pública. In:: CONGRESO INTERNACIONAL DEL CLAD SOBRE LA REFORMA DEL ESTADO Y DE LA Administración PÚBliCA, 6, 2001, Buenos Aires, Argentina, 5 a 9 noviembre. 2001, pp. 1-10.

ARthur, W. Brian. Positive Feedbacks in the economy. Scientific American, n. 262, p. 92-99, 1990.

BAKVIS, Herman; Brown, Douglas. Policy coordination in federal systems: comparing intergovernmental processes and outcomes in Canada and the United States, Publius: The Journal of Federalism, v. 40, n. 3, p. 484-507, 2010.

BAE, Jungah; FEIOCK, Richard C. Managing multiplexity: coordinating multiple services at a regional level. State and Local Government Review, v. 44, n. 2, p. 162-68, 2012.

BATISTA, Jacqueline A. Colhendo frutos a cada passo. Revista Colaboração, ano 1, n. 1, p. 12-15, 2018.

BEL, Germà; MILDRED, E. Warner. Factors explaining inter-municipal cooperation in service delivery: a meta-regression Analysis. Journal of Economic Policy Reform, v. 19, n. 2, p. 91-115, 2016.

BEL, Germà; XAVIER, Fageda; MUR, Melania. Does cooperation reduce service delivery costs? Evidence from residential solid waste services. Journal of Public Administration Research and Theory, v. 24, n. 1, p. 85-107, 2014.

BoGASON, Peter. Changes in the Scandinavian model: from bureaucratic command to interorganizational negotiation. Public Administration, v. 76, p. 335-354, 1998.

Bolleyer, Nicole; BöRzel, Tanja A. Balancing integration and flexibility in the European Union: constitutional dispositions and dynamics of coordination. Comparative European Politics, v. 12, n. 4/5, p. 384-403, 2014.

BRown, Trevor L.; POTOSKI, Matthew. Transaction costs and institutional explanations for government service production decisions. Journal of Public Administration Research and Theory, v. 13 , n. 4, p. 441-68, 2003.

CALDAS, Eduardo L.; Cherubine, Marcela B. Condições de sustentabilidade dos consórcios intermunicipais. In: CHERUBINE, Marcela; TREVAS, Vicente. Consórcios públicos e as agendas do Estado brasileiro. São Paulo: Fundação Perseu Abramo, p. 55-70, 2013.

CARR, Jered B.; HAWKINS, Christopher V.; WeSTBERG, Drew E. An exploration of collaboration risk in joint ventures: perceptions of risk by local economic development officials. Economic Development Quarterly, v. 31, n. 3, p. 210-27, 2017.

Coutinho, Frederico M. A. Os Consórcios Públicos como Instrumento Potencializador de Políticas Públicas. In: Encontro DA ANPAD, 30, 2006, Salvador, Brasil, pp. 1-16.

Cravacuore, Daniel A.; Clemente, Adriana R. El Proceso Reciente de Asociativismo Intermunicipal en Argentina. In: El Congreso InTERnACIONAL del CLAD SOBRE LA Reforma DEL ESTADO Y DE LA AdMINISTRACIÓn PÚBLICA, 11, Guatemala, Guatemala, 7-10 noviembre, 2006. Pp. 1-15.

CRUz, Livia G. B. Educação e arquiteturas territoriais: possibilidades e limites para melhoria das 
condições de ensino e aprendizagem da educação pública municipal brasileira. Dissertação de Mestrado em Administração Pública e Governo. Escola de Administração de Empresas de São Paulo, 2014.

CrUZ, Maria C. M. T.; ARAúJo, Fátima F.; BATISTA, Sinoel. Consórcios numa perspectiva históricoinstitucional. Cadernos Adenauer, v. XII, p. 111-124, 2011.

CURY, Carlos R. J. Sistema Nacional de Educação: Desafio para uma Educação Igualitária e Federativa. Educação \& Sociedade, v. 29, n. 105, p. 1187-1209, 2008.

DANIEL, Celso. Autonomia municipal e as relações com os estados e a União. In: HofMEISTER, Wilhelm; BRASILIENSE, José M. C. Federalismo na Alemanha e no Brasil. Fundação Konrad Adenauer: São Paulo, p. 205-216, 2001.

DI PORTO, Edoardo; PATY, Sonia. Cooperation among local governments to deliver public services. Politics \& Policy, v. 46, n. 5, p. 790-820, 2018.

DIEGUEZ, Rodrigo C. Consórcios intermunicipais em foco: debate conceitual e construção de quadro metodológico para análise política e institucional. Cadernos de Desenvolvimento, v. 6, n. 9, p. 291-319, 2011.

FEIOCK, Richard C. The institutional collective action framework. Policy Studies Journal, v. 41, n. 3, p. 397-425, 2013.

FEIOCK, Richard C. Rational choice and regional governance. Journal of Urban Affairs, v. 29, n. 1, p. 47-63, 2007.

FEIOCK, Richard C.; SCHOLTZ, John T. (eds.) Self-organizing Federalism: collaborative mechanisms to mitigate institutional collective action dilemmas. Cambridge: Cambridge University Press. 2009.

FruG, Gerald E. City making: building communities without building walls. Princeton: Princeton University Press. 2001.

GerRING, John Case study research. Principles and practices. Cambridge: Cambridge University Press. 2007.

GRIN, Eduardo J.; ABRUCIO, Fernando L. Um panorama sobre a cooperação intermunicipal no Brasil: avanços e desafios para gerar cidades mais sustentáveis. In: CONGRESO INTERNACIONAL DEL CLAD SObRe LA Reforma del Estado y de LA AdMinistración PúblicA, 21, 2016, Santiago de Chile, 8-11 noviembre, 2016. pp. 1-31.

GRIN, Eduardo J.; ABRUCIO, Fernando L. La cooperación intermunicipal en Brasil frente al espejo de la historia: antecedentes críticos y la dependencia de la trayectoria después de la creación de la Ley de los Consorcios Públicos. Revista Políticas Públicas, v. 10, p. 1-27, 2017.

Grin, Eduardo J.; Segatto, Catarina I.; AbRucio, Fernando L. El asociativismo intermunicipal en Brasil. In: Cravacuore, Daniel A.; CHACON, Andrés. El asociativismo intermunicipal en América Latina. Santiago de Chile: Universidad Tecnológica Metropolitana, 2016. p. 65-104.

HALL, Peter A.; TAYLOR, Rosemary S. R.. As três versões do neo-institucionalismo. Lua Nova Revista de Cultura e Política, n. 58, p. 193-223, 2003. 
HAWKINS, Christopher V. Competition and Cooperation: Local Government Joint Ventures for Economic Development. Journal of Urban Affairs, v. 32, n. 2, p. 253-75, 2010.

HAWKINS, Christopher V. Prospects for and barriers to local government joint ventures. State and Local Government Review, v. 41, n. 2, p. 108-19, 2009.

Hefetz, Amir; Warner, Mildred E.; Vigoda-Gadot, Eran. Privatization and intermunicipal contracting: the US local government experience 1992-2007. Environment and Planning C: Government and Policy, v. 30, n. 4, p. 675-92, 2012.

HULST, Rudie; VAN MONTFORT, André. Inter-municipal cooperation in Europe. AA Dordrecht: Springer. 2007.

HULST, Rudie; VAN MONTFORT, André Institutional features of cooperation: cooperative arrangements and their national contexts. Public Policy and Administration, v. 27, n. 2, p. 121-44, 2012.

IMMERGUT, Ellen M. The rules of the game: the logic of health policy-making in France, Switzerland, and Sweden. In: STEINMO, Sven; THELEN, Kathleen; LONGSTRETH, Frank. Structuring politics: historical institucionalism in comparative analysis. Cambridge: Cambridge University Press, 1992. p. 57-89.

IMMERgut, Ellen M. The teoretical core of the New Institucionalism. Politics \& Society, v. 26, n. 1, p. 5-34, 1998.

KLOK, Pieter-Jan J. et al. Intermunicipal cooperation in the Netherlands: the costs and the effectiveness of polycentric regional governance. Public Administration Review, 0 (0), p. 1-10, 2018.

Kwon, Sung-Wook; FeIOCK, Richard C. Overcoming the Barriers to cooperation: intergovernmental service agreements. Public Administration Review, v. 70, n. 6, p. 876-84, 2010.

LACKEY, Steven B.; FreshWATER, David; RUPASInghA, Anil. Factors influencing local government cooperation in rural areas: evidence from the Tennessee Valley. Economic Development Quarterly, v. 16, n. 2, p. 138-54, 2002.

LACZYNSKI, Patricia S. Políticas redistributivas e a redução da desigualdade: a contribuição potencial dos consórcios intermunicipais. Tese de doutorado. Escola de Administração de Empresas de São Paulo. 2012.

LOWERY, David A. Transactions Costs Model of metropolitan governance: allocation versus redistribution in urban America. Journal of Public Administration Research and Theory, v. 10, n. 1, p. 49-78, 2000.

LUBeLL, Mark; SCHneIDER, Mark; SCHOlz, John T.; MeTE, Mihriye. Watershed partnerships and the emergence of collective action institutions. American Journal of Political Science, n. 46, p. 148-63, 2002.

OfICINA Municipal (s/d). O que é o CIVAP? Como está a educação na região? Apresentação.

Pereira, Maria C. Produto II: Relatório Final. Relatório Técnico. Mimeografado. 2014. 
PIerson, Paul. Politics in time: history, institutions, and social analysis. Princeton: Princeton University Press. 2004.

PoluIT, Christopher. Joined-up government: a survey. Political Studies Review, v. 1, p. 34-49, 2003.

Post, Stephanie S.. Local government cooperation: the relationship between metropolitan area government geography and service provision. In: ANNUAL MEETING OF THE AMERICAN POLITICAL SCIENCE AsSOCIATION, Boston, August 29-September 1, 2002.

Ramos, Mozart N.; ABrucio, Fernando L.. Apresentação. In: Abrucio, Fernando L.; RAMOs, Mozart N. Regime de colaboração e associativismo territorial: arranjos de desenvolvimento da educação. São Paulo: Fundação Santillana, 2012. p. 11-16.

RodRïGUEZ-OrEgGIA, Eduardo; GUTIÉRREZ, Rodolfo T. La cooperación intermunicipal en México Barreras e incentivos en la probabilidad de cooperar. Gestión y Política Pública, v. 15, n. 2, p. 393409, 2006.

Segatto, Catarina I. Policy diffusion in subnational governments: State-local relationships in the Brazilian education policy. Regional \& Federal Studies, v. 28, n. 1, p. 79-100, 2018.

SegatTo, Catarina I.; ABRUCIO, Fernando L. Os múltiplos papéis dos governos estaduais na política educacional brasileira: Os casos do Ceará, Mato Grosso do Sul, São Paulo e Pará. Revista de Administração Pública, v. 52, n. 6, p. 1179-1193, 2018.

SelzNICK, Philip. An approach to a Theory of Bureaucracy. American Sociology Review, v. 8, n. 1, p. 47-54, 1984.

STRELEC, Thamara C. Relações intergovernamentais no contexto educacional brasileiro: um estudo a partir dos acordos de cooperação nas políticas públicas em educação. Tese de doutorado. Universidade Estadual de Campinas. 2017.

TAVARES, Antonio F.; Felock, Richard C. (2018). Applying an institutional collective action framework to investigate intermunicipal cooperation in Europe. Perspectives on Public Management and Governance, v.1, n. 4, p. 229-316, 2018.

WALLNER, Jennifer. Learning school: Federalism and public schooling in Canada. Toronto: University of Toronto Press. 2014.

WARner, Mildred; Hefetz, Amir. Applying market solutions to public services: an assessment of efficiency, equity, and voice. Urban Affairs Review, v. 38, n. 1, p. 70-89, 2002.

WATTS, Ronald L. Origins of cooperative and competitive federalism. In: GreER, S. L.. Territory, democracy and justice: Regionalism and federalism in Western democracies. New York: Palgrave MacMillan, 2006. p. 201-223.

WEIR, Margareth. When does politics create policy? The organizational politics of change. In: ShapIRo, I.; SKowroneK, S.; Galvin, D. Rethinking Political Institutions. New York: New York University Press, 2006. p. 171-186.

\section{Outras fontes}


Consórcio Intermunicipal do Vale do Paranapanema (Civap). Resolução no. 001, de 25 de junho de 2.015. Institui a Câmara Técnica de Educação do Consórcio Intermunicipal do Vale do Paranapanema - Civap.

Consórcio Intermunicipal do Vale do Paranapanema (Civap). Estatuto. Mimeografado.

Conselho nacional da Educação. Parecer CNE/CEB no 9/2011. Brasília: 2011.

\section{Sítios consultados}

Instituto BRASileiro de Geografia e Estatística. Pesquisa de Informações Básicas Municipais. Disponível em: < https://ww2.ibge.gov.br/home/estatistica/economia/perfilmunic/defaulttab1_ perfil.shtm >. Acesso: 03 jun. 2019.

InStituto BRAsileiro de Geografia e Estatística. Estimativas de população enviada ao TCU. Disponível em: < https://www.ibge.gov.br/estatisticas/sociais/populacao/9103-estimativas-depopulacao.html?edicao=16985\&t=resultados $>$. Acesso: 20 Maio 2019.

Instituto Brasileiro de Geografia e Estatística. Produto Interno Bruto dos Municípios. Disponível em" <https://www.ibge.gov.br/estatisticas/economicas/contas-nacionais/9088-produto-internobruto-dos-municipios.html?edicao=18760\&t=resultados > Acesso: 14 maio 2019.

FEDERAÇÃo dAS Indústrias do ESTADo do RIO DE JANEIRO. Índice Firjan de Gestão Fiscal. Disponível em: <https://www.firjan.com.br/ifgf/downloads/ >. Acesso: 08 julho 2019.

PNUD. Atlas de Desenvolvimento Humano do Brasil. Disponível em: < atlasbrasil.org.br/2013/ >. Acesso: 12 junho 2019.

Instituto nacional de Estudos e Pesquisas Educacionais Anísio Teixeira (Inep). Censo da Educação Básica Brasil. Disponível em: <http://portal.inep.gov.br/web/guest/educacao-basica/ ideb/resultados.> Acesso: 2 julho 2019.

Consórcio Intermunicipal do Vale do Paranapanema (Civap). Consórcio Intermunicipal do Vale do Paranapanema. Disponível em: <https://www.civap.com.br/>. Acesso: 12 junho 2019.

\section{Eduardo José Grin}

(iD) https://orcid.org/ 0000-0002-0488-8487

Doutor em Administração Pública e Governo (Fundação Getulio Vargas-SP). Mestre em Ciência Política (USP). Professor da Escola de Administração de Empresas de São Paulo e Pesquisador do Centro de Estudos em Administração Pública e Governo da Fundação Getúlio Vargas/SP.

E-mail: eduardo.grin@fgv.br

\section{Catarina lanni Segatto}

(iD) https://orcid.org/ 0000-0002-5094-8225

Mestre e doutora em Administração Pública e Governo (Fundação Getulio Vargas-SP). Professora Visitante da Universidade Federal do ABC e Pesquisadora do Centro de Estudos em Administração Pública e Governo da Fundação Getúlio Vargas/SP.

E-mail: catarina.segatto@gmail.com 